\title{
FURTHER EVIDENCE OF LINKAGE WITH CROSSING OVER IN OENOTHERA ${ }^{1}$
}

\author{
GEORGE H. SHULL \\ Privceton Universiby, Princeton, New Jersey
}

Received November 22, 1922.

TABLE OF CONTENTS

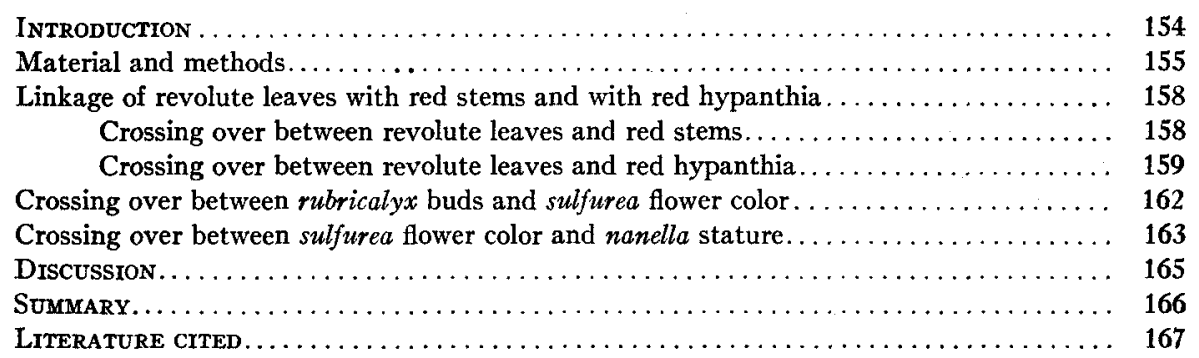

\section{INTRODUCTION}

On several occasions during the past few years I have reported the occurrence of partial linkages in Oenothera, which indicate that nearly all of the genetically studied differential characters in this genus have their determining factors in a single chromosome pair or linkage group.

Gates (1922) has recently urged that the cytological observations on Oenothera are not favorable to the view that crossing over takes place in the Oenotheras. In view of this statement it seems desirable to give some additional cases of linkage which have been observed, and which are so indubitable as to lead one confidently to predict that when the cytologists have finally identified the mechanism of crossing over, they will find that mechanism present in the Oenotheras just as in other organisms.

The linkages here considered involve (a) the relation between the factor for revolute leaves (funifolia) and that for red hypanthia (rubricalyx); (b) between revolute leaves and red stems; (c) between rubricalyx buds and sulfurea flower color; and (d) between sulfurea flower color and nanella stature.

${ }^{1}$ The experimental cultures, which form the basis of the present paper, were supported in part by a grant from the Bache Fund of the National Academy of Sciences.

GeNETiCs 8: 154 Mr 1923 
The material which forms the basis of these results traces through strictly controlled pedigree cultures to four separate original accessions as follows:

(a) Ten rosettes of Oenothera Lamarckiana were collected in nature by Dr. Hugo DE VRIEs, in the field at Hilversum, Holland, where he had secured the basic material for his own Oenothera studies some twenty years earlier. These rosettes were received at the STATION FOR EXPERIMENTal Evolution, April 7, 1905, and have formed the basis of a crossbred strain which is still being maintained, in which no cross closer than between second cousins has been made. The factor $f$ for revolute leaves originated as a gene mutation in this material, and resulted in a mutant form known as mut. funifolia which has been described and figured in a recent issue of the Journal of Heredity (SHull 1921).

(b) The rubricalyx factor $R^{h}$ was first introduced to my cultures (SHUll 1914) by a shipment of rosettes received in June, 1912, from Dr. A. F. Blakeslee, then of the Storrs Agricultural College, Storrs, Connecticut, who had grown them from unguarded seeds received from Dr. R. R. Gates. This material showed by its segregations that it contained the rubricalyx factor in heterozygous state, just as Gates had found to be the case in all his earlier studies of this form. The factor $n$ for nanella stature, involved in the cultures referred to in the present paper, was probably received likewise by way of these same rubricalyx rosettes in which it was present as a cryptomere, though it has in the meantime passed through a number of segregations from various crosses. I have also had nanella, of course, as a segregate or as a mutation in cultures of diverse origins, but these other nanellas have not been used in the experiments here reported.

(c) A second accession of rubricalyx material was received December 18, 1914 from Sutton \& Sons, Reading, England, to whom Gates sold his homozygous strain of this form. Through the kindness of ARTHUR W. Sutton, Esq., a single typical specimen was, at my request, carefully enclosed in a paper bag and self-pollinated by hand, and it is the guarded seed from this plant which has supplied the rubricalyx factor used in most of my more recent studies. This material proved to be, as was anticipated, homozygous with respect to the factor $R^{h}$ which produces the intense reddening of the hypanthia of the buds, the characteristic feature which differentiates rubricalyx from other forms of Oenothera. This rubricalyx strain was not homozygous, however, with respect to certain other factors lying in the same chromosome, for, owing to the presence of 
one of the zygote lethals, $l_{1}$ or $l_{2}$, which are characteristic of $O e$. Lamarckiana, the taxonomic form Oe. rubricalyx is, like Oe. mut. rubrinervis and Oe. mut. erythrina, a perpetual heterozygote which segregates in a $2: 1$ ratio in every generation into (1) heterozygous rubricalyx, and (2) a homozygous type resulting from the mating of two germ cells, both of which lack the zygote lethals. This homozygous segregate from rubricalyx has smaller, flatter young rosettes, with young leaves more acute, older rosettes more conspicuously crinkled, stems later in developing, usually showing a marked tendency to fall over and become crooked, buds smoother and more slender than in the heterozygous type, and of much inferior breeding capacity due to lateness of development, relatively few seeds and scanty pollen. This segregate from rubricalyx has been named latifrons.

(d) The sulfurea factor $s$ was received February 14, 1918, from Dr. BRADLEY M. Davis, who had introduced it from Oe. biennis, in which species it is regularly borne by the functional eggs, into a cross with Oe. franciscana. It came to me as selfed seeds of a segregate from this cross, which had the sulfurea flower color associated with an approximate duplication of the vegetative features (including the large size of flower and long style) of typical Oe. franciscana. This same sulfur-flowered near-franciscana segregate had also been crossed by Dr. DAvIs, reciprocally, with a pure (yellow-flowered) Oe. franciscana, and the $F_{1}$ hybrids selfed and back-crossed, reciprocally, in all possible relationships,- double reciprocal, iterative and sesqui-reciprocal,-- and samples of seeds of all these combinations were generously turned over to me by Dr. Davrs.

The sulfurea factor brought with it into these combinations the egg lethal, $l_{e}$, and the sperm lethal $l_{s}$, with which it is associated in $O e$. biennis sulfurea, and it was also noticed that while the form of the plants in these hybrid families was in all respects essentially that of pure $O e$. franciscana, there was frequent segregation of green or greenish bud-cones, which are not found in pure franciscana, but which are characteristic of Oe. biennis.

Gates has on several occasions attempted to make it appear that my results and conclusions lacked validity because of the probability that some of my material was of hybrid origin, but there is no ground for such criticism if it be understood that since 1911 I have been concerned primarily with the hereditary behavior of single genes in Oenothera and with their relationship to each other taken two by two, rather than with the relation of the tout ensemble of hybrid types compared with each other and with the tout ensemble of parental or other ancestral forms. This strictly 
Mendelian method of analysis was adopted in the belief that only thus could be found a solution of the fundamental difficulties which for so many years had baffled even the most devoted students of this group of plants, and the outcome has fully justified this belief (see SHuli 1923). But when one follows the hereditary distribution of a single dominant gene like that for rubricalyx buds there are only two states in which it can be present, namely, heterozygous or homozygous, and it will be in one or other of these states regardless of its derivation from a hybrid combination or from a pure strain.

The technique which has been employed in my work with Oenothera is essentially the same in all respects as described in one of my early papers (SHULl 1908) and it is necessary, therefore, only to remark that soon after that paper was written the use of Roman numerals was abandoned and the individuals of each pedigree have been, since that time, numbered in a single consecutive series, the individuals being designated by Arabic numerals representing their places in the series, regardless of the number of rows occupied by them in the experimental field, each row being labeled, for convenience, with the serial number of the first plant in that row.

When DE VRIES (1915) and DAVIS (1915) began urging the importance of forcing complete germination of seeds I adopted the plan of submerging the seeds in water, exhausting the air completely for about two hours, and then allowing the seeds to remain submerged under ordinary atmospheric pressure for twenty-four hours before sowing in the usual earthen pans of sterilized soil. The first year of the use of this method (1916) I tested it out by the petri-dish method of DAvis, and noted that the percentage germination was fully as high in soil as in the Petri dishes. On another occasion seeds of the several lots of franciscana material mentioned above, were divided and a part of each pedigree was grown by DAvis under the technique described in his papers, and the rest treated as here described. Comparison of the results of these parallel cultures showed that there was no essential difference in the percentage of germinations secured by the two methods. The number of seeds sown in each Oenothera culture are always recorded, as are also the total germinations, so that percentage germination can be easily derived for each culture. I have not found that, in any case, complete germination brings to light classes of individuals which are not represented when germination is only partial, but nevertheless it is always advantageous to have complete germination because of the larger cultures thus secured. Since the Petri-dish method is very time-consuming, the lack of evidence that any essential improvement in genetic ratios results from its use, makes it seem more important 
to devote the time required for handling the Petri-dishes, to enlarging the number and size of the cultures; for this reason it has seemed justifiable to continue the method which I am using even though it does not make it possible to give an ocular demonstration that in any specific case germination has actually been complete.

LINKAGE OF REVOLUTE LEAVES WITH RED STEMS AND WITH

RED HYPANTHIA

In Science for September 9, 1921, it was first announced that the factor for revolute leaves is included in the same chromosome with those for seven or eight other factors then already definitely known to be associated together in a single linkage system. The basis for this conclusion, as stated in a paper read before the Second International Congress of Eugenics (Shull 1923), consisted in the fact that in the $F_{2}$ family (pedigree No. 20156), grown in 1921 from crosses made in 1919 between flat-leaved, green-coned, red-stemmed dwarfs (nanella), and the new mutant type, funifolia, which has revolute leaves, pink bud-cones and tall, green stems, consisted only of the two grandparental types (red-stemmed nanella and tall funifolia) and the $\mathrm{F}_{1}$ type, the latter being characterized by flat leaves, pink bud-cones and tall, red stems. No cases of crossing over between any two of the factors for these four alternative characteristics were noted. Likewise, an $F_{2}$ family (20110) from a cross between funifolia, with revolute leaves, green hypanthia and long styles, and rubricalyx brevistylis having flat leaves, red hypanthia and short styles, showed only the typical monohybrid splitting with respect to style length, and no case of recombination of the factors for leaf form and bud colors. With respect to these two pairs of alternative characters the grandchildren exhibited only the combinations represented by the grandparents. It was recognized that the two families just described were too small ( 30 and 61 individuals, respectively) to justify the conclusion that the factor for revolute leaves is allelomorphic to those for red stems and red hypanthia, but it was made clear that if not allelomorphic, they were at least quite closely linked.

Appropriate crosses were made for testing these linkages more adequately and the results of these tests are set forth below.

Crossing over between red stems and revolute leaves.

The cross between the revolute-leaved green-stemmed funifolia and a flat-leaved, red-stemmed nanella whose $F_{2}$ (20156) has been briefly re-described above, was made the basis of a test consisting of five back- 
crosses between as many individuals of the $F_{1}$ type (tall, flat-leaved, redstemmed), and one of their recessive funifolia sibs. The results of these five back-crosses are given in table 1.

TABLE 1

Back-cross, (green-stemmed funifolia $\times$ red-stemmed nanella) $F_{1} \times$ funifolia.

\begin{tabular}{c|c|c|c|c}
\hline \multirow{2}{*}{\begin{tabular}{c|c|c|} 
PEDIGREE \\
NUMBER
\end{tabular}} & \multicolumn{2}{|c|}{ FLAT-LEAVED } & \multicolumn{2}{|c}{ REVOLUTE-LEAVED } \\
\cline { 2 - 4 } & $\begin{array}{c}\text { Red- } \\
\text { stemmed }\end{array}$ & $\begin{array}{c}\text { Green- } \\
\text { stemmed }\end{array}$ & $\begin{array}{c}\text { Red- } \\
\text { stemmed }\end{array}$ & $\begin{array}{c}\text { Green- } \\
\text { stemmed }\end{array}$ \\
\hline 2153 & 30 & 0 & 1 & 36 \\
2154 & 37 & 0 & 1 & 56 \\
2155 & 42 & 0 & 0 & 32 \\
2156 & 1 & 0 & 0 & 16 \\
2157 & 17 & 0 & 0 & 27 \\
\hline Totals & 127 & 0 & 2 & 167 \\
\hline
\end{tabular}

The two individuals with red stems and revolute leaves did not differ in any way from their funifolia sibs except in the possession of the intensely reddened stems derived from the flat-leaved nanella grandparent, and there is no other reasonable explanation of the occurrence of this recombination than that they resulted from crossing over. The small number of crossovers makes it clear that the numbers involved in these tests are wholly inadequate for the determination of the degree of linkage, but at least they show that the red-stem factor is separable from the flat-leaf factor, a fact which had not been demonstrated in the $F_{2}$ culture from which the set of $F_{3}$ families presented in table 1 were derived. In other words, the revolute factor, $f$, and the red-stem factor $R^{s}$, are not allelomorphic to each other.

\section{Crossing over between revolute leaves and red hypanthia}

A double series of tests of the linkage relations between the red hypanthia of rubricalyx and the revolute leaves of funifolia was carried out on an $F_{1}$ family (2016) which had been specially established for this purpose through a cross made in 1920 between rubricalyx and funifolia. In this series ten $F_{1}$ plants (all flat-leaved, with rubricalyx buds) were selfed, and the same plants were also back-crossed to the double recessive funifolia (revolute leaves and green hypanthia).

Owing to the fact that the funifolia used in this cross carried the balanced zygote lethals, $l_{1} l_{2}$, characteristic of Lamarckiana, while rubricalyx possesses one of these lethals, the $\mathrm{F}_{1}$ family split into Lamarcki- 
ana and rubricalyx with respect to the vegetative habit, though all plants had flat leaves and red hypanthia. The expected result of selfing the Lamarckiana-type $\mathrm{F}_{1}$ plants, if there were no crossing over, would be that they should breed true to the rubricalyx buds and flat leaves, even though they were demonstrably heterozygous for both these characters, the breeding true being due to the fact that both homozygous types are eliminated through the normal action of the balanced lethals. On the other hand the rubricalyx type of $F_{1}$ should be expected to split into flatleaved rubricalyx (red hypanthia) and revolute-leaved funifolia with green hypanthia in a ratio $2: 1$, or else not to split, depending on whether the funifolia factor lay in the lethal-bearing chromosome, or in the nonlethal-bearing chromosome. Only eight of the selfings resulted in progenies, and these are given in table 2.

TABLE 2

Results of selfing $F_{1}$ plants from the cross rubricalyx $\times$ funifolia.

\begin{tabular}{|c|c|c|c|c|}
\hline \multirow{2}{*}{$\begin{array}{l}\text { PEDIGREE } \\
\text { NUMBER }\end{array}$} & \multicolumn{2}{|c|}{ FLAT-LEAVED } & \multicolumn{2}{|c|}{ REVOLUTE-LEAVED } \\
\hline & $\begin{array}{c}\text { Red } \\
\text { hypanthia }\end{array}$ & $\begin{array}{c}\text { Green } \\
\text { hypanthia }\end{array}$ & $\begin{array}{c}\text { Red } \\
\text { hypanthia }\end{array}$ & $\begin{array}{c}\text { Green } \\
\text { hypanthia }\end{array}$ \\
\hline 2158 & 45 & 0 & 0 & 0 \\
\hline 2162 & 71 & 0 & 1 & 0 \\
\hline 2164 & 71 & 0 & 0 & 0 \\
\hline 2167 & 58 & 1 & 0 & 25 \\
\hline 2169 & 41 & 9 & 14 & 6 \\
\hline 2171 & 60 & 2 & 3 & 22 \\
\hline 2173 & 91 & 2 & 1 & 37 \\
\hline 2175 & 68 & 3 & 0 & 14 \\
\hline
\end{tabular}

It is clear that the families in table 2 fall into three categories: (a) The first three were derived from Lamarckiana-like $\mathrm{F}_{1}$ plants, (possessing the characteristic zygote lethals) and they show an aggregate of 187 flatleaved plants to one revolute-leaved, all with red hypanthia, the expected result as stated above, the one revolute-leaved plant being due, presumably, to crossing over between the funifolia factor and one of the zygote lethals. (b) Four families $(2167,2171,2173,2175)$ gave essentially the result expected from the rubricalyx type of $F_{1}$, the summation of these four families giving 277 flat-leaved with red hypanthia : 8 flat-leaved with green hypanthia : 4 revolute-leaved with red hypanthia : 98 revoluteleaved with green hypanthia. This very characteristic linkage ratio is defective chiefly in the fact that the number of the revolute type is considerably too low, so that the ratio approximates $3: 1$ instead of the $2: 1$ 
expected, but this is quite probably due to a differential elimination affecting the revolute type more strongly than the flat-leaved; (c) finally, there is the remarkable exceptional family (2169) in which there seems to be no linkage, the ratio $41: 9: 14: 6$ being as close an approximation to the dihybrid ratio $39: 13: 13: 4$ as could be reasonably expected in a family of only 70 individuals.

The significance of this family is not yet known, but it may be pointed out that this is not the only case of what seems to be a complete break in a linkage relation in Oenothera. I am inclined at present at least to interpret BARTLETT and CoBB'S $(1919,1921)$ Mendelizing strain of Oe. pratincola mut. formosa as representing a case of this kind. It may be suggested that the possible translocation of a chromosome might account for such a case.

Of the ten back-crosses involving the same parents as those whose progenies by selfing are included in table 2, nine produced offspring, and these nine families are given in table 3 , together with two families from other experiments which happened to represent the same type of breeding.

TABle 3

Back-crosses of (funifolia $\times$ rubricalyx) $F_{2}$ with funifolia.

\begin{tabular}{c|c|c|c|c}
\hline \multirow{2}{*}{\begin{tabular}{c|c|c} 
PEDIGREE \\
NUMBER
\end{tabular}} & \multicolumn{2}{|c|}{ FLAT-LEAvEd } & \multicolumn{2}{|c}{ REvolute-Lzaved } \\
\cline { 2 - 5 } & $\begin{array}{c}\text { Red } \\
\text { hypanthia }\end{array}$ & $\begin{array}{c}\text { Green } \\
\text { hypanthia }\end{array}$ & $\begin{array}{c}\text { Red } \\
\text { hypanthia }\end{array}$ & $\begin{array}{c}\text { Green } \\
\text { hypanthia }\end{array}$ \\
\hline 2159 & 56 & 2 & 2 & 22 \\
2161 & 79 & 1 & 3 & 22 \\
2163 & 84 & 1 & 1 & 29 \\
2165 & 67 & 2 & 2 & 27 \\
2166 & 95 & 2 & 1 & 56 \\
2168 & 35 & 1 & 0 & 25 \\
2170 & 40 & 0 & 1 & 34 \\
2172 & 74 & 6 & 3 & 71 \\
2174 & 57 & 1 & 3 & 60 \\
21181 & 44 & 0 & 1 & 19 \\
21185 & 45 & 1 & 0 & 29 \\
\hline Total & 676 & 17 & 17 & 394 \\
\hline
\end{tabular}

The consistency of the results shown in this table is impressive. The very considerable deficiency in the number of revolute-leaved plants may possibly be due to elimination on purely physiological grounds. As linkage ratios are most satisfactorily derived from back-cross tests the data in table 3 may be taken as the best basis for calculating such a ratio. If the total data are taken, the ratio is 3.08 percent, but if the ratio be 
based only on the flat-leaved group, as may be suggested because of the probable differential elimination of revolute-leaved, green-hypanthium plants, the ratio becomes 2.45 percent.

CROSSING OVER BETWEEN rubricalyx BUDS AND sulfurea FLOWER COLOR

In 1918 a cross was made between Oe. franciscana sulfurea and a rubricalyx-budded nanella, and also between franciscana sulfurea and a rubricalyx-budded brevistylis. As both of the rubricalyx plants used in these crosses were heterozygous for bud color, the $F_{1}$ families (18186, 18187 ) both showed splitting in regard to this character. The $F_{2}$ families produced by selfing rubricalyx-budded $F_{1}$ plants were grown in 1920, and the results are presented in table 4.

TABLE 4

$F_{2}$ families produced by selfing red-hypanihium $F_{1}$ plants from the cross greenhypanthium sulfur $\times$ red-hypanthium yellow.

\begin{tabular}{c|c|c|c|c}
\hline \multirow{2}{*}{$\begin{array}{c}\text { PED IGREE } \\
\text { NUMBER }\end{array}$} & \multicolumn{2}{|c|}{ RED HYPANTHIA } & \multicolumn{2}{|c}{ GREEN HYPANTHIA } \\
\cline { 2 - 4 } & Yellow & Sulfur & Yellow & Sulfur \\
\hline 19168 & 43 & 0 & 11 & 5 \\
19176 & 60 & 0 & 7 & 10 \\
19182 & 139 & 2 & 5 & 2 \\
19183 & 104 & 1 & 2 & 3 \\
19185 & 140 & 2 & 4 & 17 \\
19188 & 95 & 1 & 5 & 6 \\
\hline Total & 581 & 6 & 34 & 43 \\
\hline
\end{tabular}

It was not understood at that time that the franciscana sulfurea was carrying with it the egg lethal which had accompanied the sulfurea factor when the latter was introduced from biennis into franciscana by Dr. B. M. DAvis as indicated above. On this account the results from these crosses seemed somewhat chaotic and incomprehensible, though the results in the various families appeared to be fairly consistent. With the demonstration of the gamete lethals, as briefly described in my. Eugenics CoNGress paper, the meaning of the results in the $F_{2}$ families became clear. Sulfurea segregates could appear only when the sulfurea factor was separated from the egg lethal by crossing over, and it is for this reason that so few sulfureas appeared in the $F_{2}$. It seems proper to assume, however, that the crossing over between the sulfurea factor and the egg lethal is distributed homogeneously over the two bud-color classes, so that the proportionality between the two groups of sulfur-flowered plants 
will not have been notably affected. The correlative crossover class in which the yellow factor was associated with the egg lethal will have produced no corresponding aberration in the yellow-flowered classes. If these assumptions are correct we may calculate a crossover ratio, from the data of table 4 notwithstanding the presence of the egg lethal. As in other cases described in this paper, the calculation may be based on the total data, or only on the more numerous classes, but it must be noted that these families are the result of selfing, and that, in consequence, the linkage ratio can not be derived so simply as in the case of the back-crosses. It seems better on this account to use for this purpose only the yellowflowered classes. If we assume the gametic ratio to have the form $n: 1: 1: n$, the value of $n$ can be easily derived from the equation, $\left(3 n^{2}+\right.$ $4 n+2):(2 n+1)=581: 34 \therefore n=10.53$, and the crossover ratio, $10.53: 1$, is 8.7 percent.

The linkage between rubricalyx buds and yellow flower-color has now been tested also by a cross of the "repulsion" type, as follows: One of the two rubricalyx sulfurea plants in family 19185 (see table 4) was crossed onto a funifolia erythrina (yellow-flowered with green hypanthia and red bud-cones) from family 1994 . The pollen parent in this cross was heterozygous with respect to bud color and the $F_{1}$ family (20112) split into 60 rubricalyx (red hypanthia) and 26 erythrina (green hypanthia). One of the rubricalyx plants of this $F_{1}$ family was back-crossed to the double recessive sulfurea with green hypanthia, and gave a progeny (21170) consisting of 6 yellow-flowered rubricalyx, 59 sulfur-flowered rubricalyx, 95 yellow-flowered with green hypanthia and 4 sulfur-flowered with green hypanthia. From this family a crossover ratio of 6.1 percent is calculated. The significance of the deficiency in the sulfurea class is not yet fully understood, but a similar deficiency has been noted in other crosses, as already pointed out in the rather extensive tests of linkage between flower color and stem color reported in my EugENICS Congress paper.

\section{CROSSING OVER BETWEEN sulfurea FLOWER COLOR AND nanella STATURE}

In the summer of 1918 I made a cross between Oe. franciscana sulfurea having tall green stems and pink bud-cones, and a red-stemmed greenbudded, yellow-flowered dwarf (nanella). The $F_{1}$ family (18185) grown in 1919 consisted of tall red-stemmed yellow-flowered plants. The $F_{2}$ families from this cross gave in 1921 the beautiful linkage ratios between sulfur flower-color and red stem-color which were reported in brief summary in my EUGENICs Congress paper. The nanella segregates in these families were mostly yellow-flowered, as was to be expected, since the Genetics 8: Mt 1923 
nanella grandparent had yellow flowers, but 2 good nanella sulfurea plants occurred among them as a result of crossing over and the more sturdy of these was used in a number of crosses, two of which form the basis of the results reported in this section.

A funifolia, newly arisen by a crossover mutation in Lamarckiana family No. 19111, was made the recipient of pollen from this nanella sulfurea and the $F_{1}$ grown in 1921.

In this family (20212) there appeared the $F_{1}$ segregation into chlorotic and full green which usually appears in crosses between Lamarckiana or its derivatives on the one hand, and franciscana and its derivatives on the other. Both groups reached maturity, the chlorotic forms suggesting late-flowering erythrina, while the full-green type was much like vigorous Lamarckiana. All of both types had tall stems, flat leaves and yellow flowers.

One plant of each $F_{1}$ type was pollinated with pollen from the double recessive nanella sulfurea, and the results of these back-crosses are given in table 5 .

TABLE 5

Back-cross tests involving the cross, tall yellow-flowered $\times$ nanella sulfurea.

\begin{tabular}{|c|c|c|c|c|}
\hline \multirow{2}{*}{$\begin{array}{l}\text { PEDIGREE } \\
\text { NUMRESR }\end{array}$} & \multicolumn{2}{|c|}{ TALI } & \multicolumn{2}{|c|}{$\begin{array}{c}\text { DWARF } \\
\text { (nanella) }\end{array}$} \\
\hline & Yellow & Sulfur & Yellow & Sulfur \\
\hline 21192 & 40 & 3 & 1 & 16 \\
\hline 21195 & 17 & 1 & 3 & 6 \\
\hline Total & 57 & 4 & 4 & 22 \\
\hline
\end{tabular}

In this case there is again a strong deficiency of the double recessive type, and it is even more reasonable than in the previous case to assume that this is due to a considerable elimination of the nanella plants by purely physiological causes. We may calculate the linkage ratio in this case as in the previous one, giving 9.2 percent or 6.7 percent, according as the total data, or only the data from the more viable group, are used.

That the crossing over in the opposite direction takes place equally well is shown by family 21197 in which the same factors were at play but derived from the parents in the reverse combination. In this case a tall sulfurea was crossed with pollen of a yellow-flowered nanella, producing, as before, a tall yellow-flowered $F_{1}$. One of these $F_{1}$ plants back-crossed to 
the double recessive nanella sulfurea, produced an $F_{2}$ family (21197) consisting of 2 tall yellow : 41 tall sulfur : 7 nanella yellow : 1 nanella sulfur. This characteristic linkage ratio shows again the marked deficiency of nanella, and gives a linkage ratio of 5.9 percent or 4.7 percent according as the calculation is based on the total data or on those for the tall group only. The numbers involved in these three families are too small, of course, to make the differences in the linkage ratios of any significance, and we can properly consider the results presented in this section as entirely consistent.

\section{DISCUSSION}

The experimental results presented here are fully adequate, I believe, as were those given in my Eugrnics Congress paper (Shull 1922) to demonstrate the regular occurrence of crossing over in the group of Oenotheras with which I have been working. A failure to find chromosomes lying side by side or twisting about each other can not in any way set aside these genetical proofs that linkage with crossing over does occur. It may, however, affect our views as to the validity of the chiasmatype theory of crossing over, a theory of whose correctness I have never been fully convinced.

The conspicuous configuration of the chromosomes in Oenothera into circles consisting of 2 or 4 chromosomes joined end to end (DAvis 1919, Cleland 1922) raises the question whether it may not be possible that such a group of chromosomes represents the basis of a linkage group instead of the single chromosome pair. If this suggestion should be made with a view to avoiding the necessity for the assumption of crossing over within the limits of the single pair of chromosomes, it can be at once answered in the negative, in so far as the attainment of that particular object is concerned, because of the large number of separable factors known to be associated together in this one linkage group. The following factors are now identified as belonging to the first linkage group: (1) $n$, for nanella stature; (2) $R^{h}$, red hypanthium of rubricalyx; (3) $R^{c}$ red cone and green hypanthium; (4) $r^{c}$, buds free from red pigment; (5) $R^{\boldsymbol{b}}$, intensely reddened stems; (6) $l_{1}$, and (7) $l_{2}$, zygote lethals; (8) $s$, sulfur-colored flowers; (9) $l_{s}$, sperm lethal; (10) $l_{e}$, egg lethal; (11) $f$, revolute leaves of funifolia and of Oe. pratincola mut. formosa; (12) $c$, a factor which suppresses the basal branches of Lamarckiana, giving rise to an undescribed mutation known as columnaris; (13) $N_{p}$, factor for narrow petals. This list now includes nearly twice the haploid number of chro- 
mosomes, so that there can be no escape from the conclusion that crossing over in Oenothera is an "intrazygous," not an "interzygous" phenomenon.

There is no disposition to claim that the linkage ratios indicated by the results thus far observed and presented are approximately correct values. It is fully recognized that every ratio needs to be based upon a much larger amount of data, but the accumulation of the requisite amount of data will require years of work unless these problems are taken up by a considerable number of investigators.

\section{SUMMARY}

The cytological studies of Oenothera have thus far failed to discover a relation between the homologous chromosomes which seems favorable to the assumption that an interchange of genes between them may take place by the method of chiasmatypy.

This fact must not be allowed, however, to throw any doubt on the occurrence of crossing over in this group, as demonstrated by appropriate breeding experiments. The following cases of partial linkage are presented in this paper:

1. Revolute leaves of the mutant type funifolia and the stem color of a red-stemmed nanella have in most cases separated during $\mathrm{F}_{1}$ gametogenesis, but in 2 individuals among 296 the red stems and revolute leaves have been associated through the ability of the genes for these two characters to enter the same gamete.

2. Revolute leaves and red hypanthia showed typical linkage ratios when the $F_{1}$ plants were back-crossed to the double recessive, with crossing over to an extent indicated approximately by the ratios 2.45 and 3.08 percent.

When the $F_{1}$ plants were selfed the ratios were modified by the presence of one or more zygote lethals, and one such self-fertilization gave a small family whose composition indicated that the usual linkage was absent.

3. Red hypanthia of rubricalyx are linked with sulfurea flower color with a frequency of crossing over which may be roughly indicated by the values 8.7 and 6.1 , derived from two types of matings.

In one series of matings in this section the ratios are notably modified by the presence of an egg lethal, brought into the material from Oenothera biennis, from which the sulfurea factor had been derived.

4. Sulfurea flower color and nanella stature are shown to be partially linked, with a ratio of crossing over variously calculated as $4.7,5.9,6.7$ or 9.2 percent. 
The number of factors recognized as being associated together in a single linkage group is now thirteen, or almost twice as many as the haploid number of chromosomes. This fact makes it necessary to assume that crossing over takes places within the single chromosome pair. The apparent cohesion of non-homologous chromosomes is not an adequate explanation.

\section{LITERATURE CITED}

Cleland, Ralph E., 1922 The reduction divisions in the pollen mother cells of Oenothera franciscana. Amer. Jour. Bot. 9: 391-413. 3 plates.

CoBb, FrIEdA, and BARTLeTr, H. H., 1919 On Mendelian inheritance in crosses between mass-mutating and non-mass-mutating strains of Oenothera pratincola. Jour. Washington Acad. Sci. 9: 462-483.

1921 A case of Mendelian inheritance complicated by heterogametism and mutation in Oenothera pratincola. Genetics 6: 1-42.

Davis, B. M., 1909 Cytological studies on Oenothera I. Pollen development of Oenothera grandiflora. Annals of Bot. 23: 551-571.

1915 A method of obtaining complete germination of seeds in Oenothera and of recording the residue of sterile seedlike structures. Proc. Nation. Acad. Sci. 1: 360-363.

GATES, R. R., 1922 Some points on the relation of cytology and genetics. Jour. Heredity 13: $75,76$.

Snutr, G. H., 1908 The pedigree culture: its aims and methods. Plant World 11: 21-28, 55-64.

1921 Mendelian or non-Mendelian? Science N. S. 54: 213-216.

1923 Linkage with lethal factors the solution of the Oenothera problem. Proc. Second Internat. Cong. Eugenics, Vol. 1, pp. 86-99.

VRIES, HUGO DE, 1915 The coefficient of mutation in Oenothera biennis L. Bot. Gaz. 59: 169-196. 